\title{
Fiducial marks as measures of thin film crack arrest toughness
}

\author{
Alex A. Volinsky ${ }^{\text {a,*}}$, Michael L. Kottke ${ }^{\text {a }}$, Neville R. Moody ${ }^{\text {, }}$, \\ William W. Gerberich ${ }^{b}$ \\ ${ }^{a}$ Motorola, Digital DNA ${ }^{\mathrm{TM}}$ Labs, Process and Materials Characterization Lab, 2200 W. Broadway Road M-360, \\ Mesa, AZ 85202, USA \\ ${ }^{\mathrm{b}}$ Department of Chemical Engineering and Material Science, University of Minnesota, Minneapolis, MN 55455, USA \\ c Sandia National Labs, Livermore, CA 94551, USA \\ Received 30 October 2001; accepted 15 November 2001
}

\begin{abstract}
Carbon fiducial marks are formed during thin film local delamination processes induced either by indentation, forming circular blisters, or by residual stress relief through telephone cord blister formations. Hydrocarbons are sucked into the crack tip during the delamination processes, outlining the crack tip opening angle, which can be used to back calculate thin film adhesion using elastic or plastic analyses presented in the paper. (c) 2002 Published by Elsevier Science Ltd.
\end{abstract}

Keywords: Fiducial marks; Adhesion; Fracture; Delamination; Crack arrest; Crack tip opening angle; Thin films

\section{Introduction}

Thin film adhesion can be measured by means of the superlayer indentation test [1-4]. Most goodadhered thin films cannot be delaminated by means of regular indentation: films would rather deform plastically around the indenter by forming pileup. To prevent these problems a high modulus hard superlayer, capable of supporting and storing large amounts of elastic energy is deposited on top of the film of interest. Upon indentation a delamination blister forms around the indent, and its area is used to calculate the strain energy release rate (practical work of adhesion). This technique was shown to work with ductile metallic films (Al, $\mathrm{Cu}, \mathrm{Au}, \mathrm{Cr})$ [2,4-9,15], ceramic $\left(\mathrm{Ta}_{2} \mathrm{~N}\right)$ [10-12] and polymer films [16].

During indentation experiments into $\mathrm{Cu}$ thin films with a W superlayer it was found that the crack arrest marks form and correspond exactly to the blister size [13,14]. Marks are formed of carbon, and outline the crack tip, representing its geometry $[13,14]$.

\footnotetext{
${ }^{*}$ Corresponding author. Tel.: +480-655-4240; fax: +480-655-5013.

E-mail address: alex.volinsky@motorola.com (A.A. Volinsky).
} 


\section{Crack arrest (fiducial) marks}

Crack arrest marks were found after the blister removal with an adhesive tape. Scanning electron microscopy showed circles that correspond to the original blister diameter, and those were denoted as crack arrest fiducial marks $[13,14]$. Atomic force microscopy was performed to measure the feature geometry, giving a width over $1 \mu \mathrm{m}$, and a height ranging from 5 to $15 \mathrm{~nm}$. Contact and deflection AFM images of the partially removed blister showing the fiducial crack arrest marks are presented in Fig. 1.

It was originally believed that the crack arrest mark is formed by crushed $\mathrm{W}$ and/or $\mathrm{SiO}_{2}$ debris during the indentation [13]. More likely, however, radial cracking allowed laboratory air with moisture, hydrocarbons and surface debris to be sucked into the blister [14]. The exact source of contamination would be identified later, but whatever the source is, relatively mobile moisture, hydrocarbons and small debris particles were sucked into the crack tip leaving the fiducial mark detected in Fig. 1.

\section{Slow crack growth analysis}

Upon blister removal with a scotch tape the crack tip residue splits into two fiducial marks, leaving one on the film and substrate sides as shown in Fig. 2. The substrate fiducial mark outlines the crack tip geometry, and its dimensions can be used to extract the thin film crack arrest toughness [13,14].

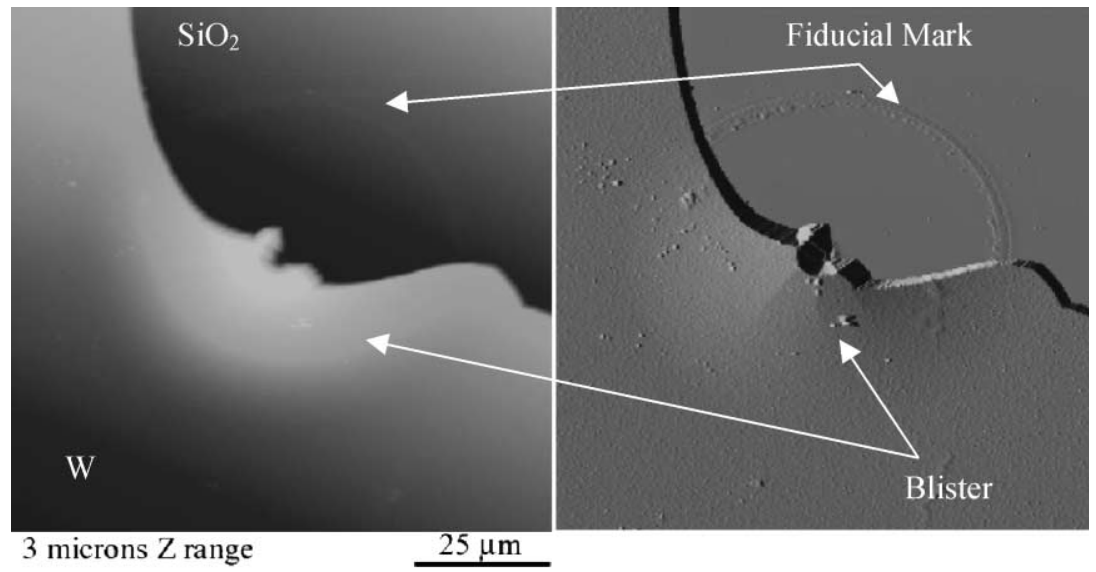

Fig. 1. AFM height and deflection images of partially removed blister, showing fiducial mark underneath.

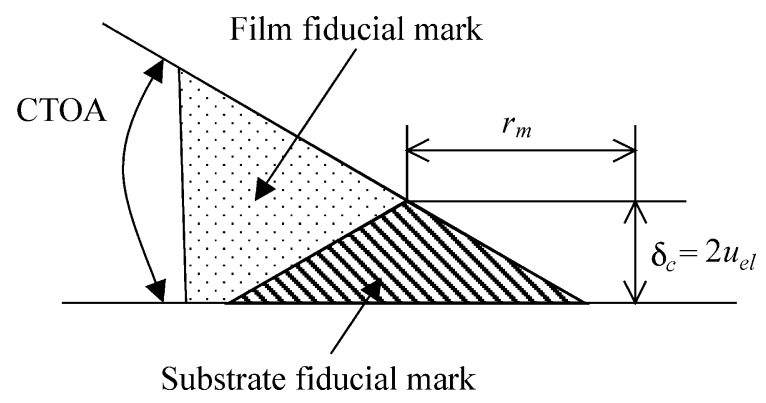

Fig. 2. Fiducial mark geometry. 
As discussed in $[2,4,15]$, brittle fracture is observed for thinner $\mathrm{Cu}$ films $(<100 \mathrm{~nm})$ on $\mathrm{Si}$ substrates without a Ti underlayer. The majority of blisters in these films are buckled, so the crack is mostly under Mode I loading. This allows us to use the elastic crack tip opening displacement expressed for the plane stress tensile loading [17]:

$$
u_{\mathrm{el}}(r)=\frac{K}{E} \sqrt{\frac{8 r}{\pi}}
$$

AFM measurements of the fiducial mark on the substrate side provide the height, $\delta_{c}=2 u_{\mathrm{el}}\left(r_{\mathrm{m}}\right)$, and the half width of the mark, $r_{\mathrm{m}}$ (Fig. 2), so $K_{\mathrm{I}}$ can be expressed as

$$
K_{\mathrm{I}}=\delta_{c} E \sqrt{\frac{\pi}{32 r_{\mathrm{m}}}} .
$$

From Eq. (2), for $\delta_{c}=8 \mathrm{~nm}$ and $r_{\mathrm{m}}=1 \mu \mathrm{m}$ one finds $K_{\mathrm{I}}=0.3 \mathrm{MPa} \mathrm{m}^{1 / 2}$. This is close to the 0.33 $\mathrm{MPa} \mathrm{m}^{1 / 2}$ value calculated from the actual $G$ measurements $\left(\sim 0.9 \mathrm{~J} / \mathrm{m}^{2}\right)$ for thinner $\mathrm{Cu}$ films using $K=(G E)^{1 / 2}$ for plane stress $[2,4,15]$. Since the analysis is purely elastic, it indirectly proves that there is not much plastic energy dissipation at the crack tip for thin $\mathrm{Cu}$ films. Previously we also employed a plasticitybased slow crack growth approach based on the Rice, Drugan and Sham (RDS) analysis of the tearing modulus, $T_{0}$ [18] to show a similar result [13]. One can obtain a simple expression for strain energy release rate in terms of the crack-tip opening angle (CTOA in Fig. 2):

$$
J_{S S}=J_{0} \exp \left(\frac{\alpha T_{0}}{\beta}\right)=J_{0} \exp \left(\frac{E \mathrm{CTOA}}{\sigma_{\text {ys }} \beta}\right),
$$

where $J_{0}$ is the initial value of the $J$ integral at crack initiation, $T_{0}$ is the tearing modulus, $\alpha \approx 1, \beta=5.1$ from the mechanics description, $E$ and $\sigma_{\mathrm{ys}}$ are modulus and yield strength. With 0.01 radians average value of the CTOA, a modulus of $120 \mathrm{GPa}$, a yield strength of $1 \mathrm{GPa}$ and $\beta=5.1$, one finds:

$$
J_{S S}=J_{0} \exp \{0.23\} \approx 1.27 J_{0}
$$

which means that during slow crack growth the strain energy release rate has barely increased for this 120 $\mathrm{nm}$ thick copper film. This again agrees with the actual measured value of $\sim 0.9 \mathrm{~J} / \mathrm{m}^{2}$ for the strain energy release rate.

\section{Carbon contamination source}

There are three possible sources for carbon: adhesive tape, the diamond indenter and hydrocarbons from the atmosphere. In our previous studies the first two sources were eliminated [13-15], and hydrocarbons from the atmosphere were proposed as a source of fiducial mark formation.

During the course of this study it was found that a similar type of contamination is present in a different film system of $\mathrm{Ti}_{X} \mathrm{WN}_{Y}$ on GaAs, where the telephone cord delaminations formed due to the high residual stress relief (Fig. 3). The carbon traces noted both on the film and substrate surfaces mimic the original telephone cord delamination pattern. Fiducial crack arrest marks are like those observed in the $\mathrm{Cu} / \mathrm{SiO}_{2}$ system. Fig. 3 also shows a carbon Auger map, where brighter areas correspond to higher carbon concentrations. There is almost no carbon present between the original phone cord delaminated areas (black regions in Fig. 3). Most of the carbon goes into the crack tip, outlining the telephone cord topography. Fiducial mark formation may also be associated with the local heating at the crack tip. The heat dissipates fast enough so that the whole sample is not heated up, although the local crack tip temperature may increase substantially. This is a very interesting phenomenon that requires further investigation. 

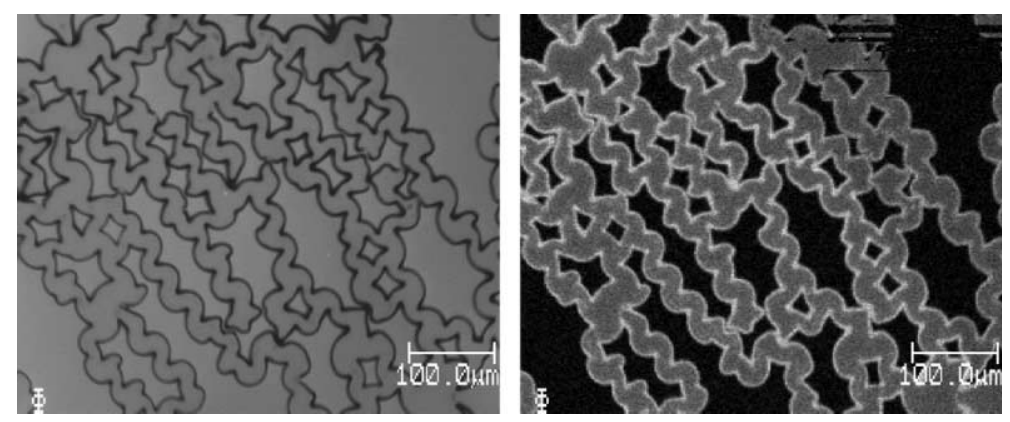

Fig. 3. SEM micrograph and corresponding Carbon Auger map of a GaAs fracture surface upon $\operatorname{TiW}_{X} \mathrm{~N}_{Y}$ film removal.

\section{Conclusions}

We have shown that fiducial marks formed in thin copper film delamination give a good measure of the crack-tip opening displacement. In turn this can be used to estimate the fracture resistance as verified by the superlayer nanoindentation technique. Both elasticity and tearing modulus estimates of the critical stress intensity agree with an independently measured fracture toughness based on the driving force for crack growth. These results strongly suggest that there was nearly negligible plasticity involved in delaminating this $120 \mathrm{~nm}$ film.

\section{Acknowledgements}

The authors would like to acknowledge support through DOE grants DE-FG02/96ER45574 and DEAC04-94AL85000. We would also like to acknowledge W. Miles Clift and Bernice E. Mills from Sandia National Lab at Livermore for Auger analysis, Indira S. Adhihetty from Motorola and Robert F. Cook from the University of Minnesota for valuable discussions.

\section{References}

[1] Kriese MD, Gerberich WW. J Mater Res 1999;14(7):3007-18.

[2] Volinsky AA, Tymiak NI, Kriese MD, Gerberich WW, Hutchinson JW. Mat Res Soc Symp Proc 1999;539:277-90.

[3] Gerberich WW, Kramer DE, Tymiak NI, Volinsky AA, Bahr DF, Kriese M. Acta Mater 1999;47(15):4115-23.

[4] Tymiak NI, Volinsky AA, Kriese MD, Downs SA, Gerberich WW. Metall Mater Trans A 2000;31A:863-72.

[5] Volinsky AA, Moody NR, Gerberich WW. MRS Symp Proc 2000, vol. 594.

[6] Moody NR, Adams D, Volinsky AA, Kriese M, Gerberich WW. Mat Res Soc Symp Proc 2000, vol. 586.

[7] Schneider JA, Guthrie SE, Kriese MD, Clift WM, Moody NR. Mat Sci Eng A (Structural Materials: Properties, Microstructure and Processing) 1999;259(2):253-60.

[8] Kriese MD, Gerberich WW, Moody NR. J Mater Res 1999;14(7):3019-26.

[9] Schneider JA, Guthrie SE, Kriese MD, Clift WM, Moody NR. Fundamentals of Nanondentation and Nanotribology Symposium 1998. pp. 347-52.

[10] Moody NR, Medlin D, Boehme D, Norwood DP. Eng Fract Mech 1998;61(1):107-18.

[11] Moody NR, Hwang RQ, Venka-Taramani S, Angelo JE, Norwood DP, Gerberich WW. Acta Mater 1998;46(2):585-97.

[12] Moody NR, Medlin D, Norwood DP, Gerberich WW, Gao H, Sundgren JE et al. Thin Films: Stresses and Mechanical Properties VI. Symposium 1997. pp. 97-102.

[13] Volinsky AA, Gerberich WW, MRS Symp Proc 1999, vol. 563, pp. $275-84$.

[14] Volinsky AA, Clift WM, Moody NR, Gerberich WW. Mat Res Soc Symp Proc 1999, vol. 586.

[15] Volinsky AA. PhD Dissertation, University of Minnesota, 2000. 
[16] Volinsky AA, Vella JB, Fowler BW, Adhihetty IS, Gerberich WW, Presented at 2001 Mechanics and Materials Summer Conference, San Diego, 2001.

[17] Lawn B. Fracture of Brittle Solids. Cambridge: Cambridge University Press; 1993.

[18] Anderson TL. In: Fracture Mechanics: Fundamentals and Applications. Boston: CRC Press; 1991. p. 219. 